\title{
O que é poesia?, de Sousa Dias
}

\author{
Eduardo Aparecido de Oliveira
}

Universidade de São Paulo

que époesia?, de Sousa Dias, nos sugere de imediato a questão sobre como, em um livro de poucas páginas, é possível abordar um assunto complexo (e com registros de linguagem tão diversificados), como a poesia. Porém, logo de início, nota-se a capacidade do autor de ir direto ao ponto e sem a necessidade de citações enciclopédicas como forma de legitimar seu pensamento. Alguns poucos teóricos são referenciados em suas análises, servindo para exemplificar, explanar o assunto que o autor estuda. Ir diretamente ao núcleo da discussão indagação que dá o título ao livro, tema clássico se pensarmos toda uma produção teórica desde a Poética à Filosofia da Composição etc. - foi pretensão de poucos. A maioria das abordagens são sucintas ou indiretas, o que não é para menos se pensarmos nas diferentes formas poéticas existentes na história da literatura.

O autor divide seu livro em curtos capítulos denominados: "Poesia, arte bilingue", onde tratará da "segunda" língua criada pela poesia; "A experiência poética", cujo intenção principal é mostrar a poesia como função da linguagem e não das experiências vividas; "Com que palavras e sem que palavras?", o autor se concentra no pensamento de Manuel Antonio Pina sobre sua criação; e o último ensaio "Partir, evadir-se, traçar uma linha", no qual questões deleuzianas sobre a escrita ganham destaque. O que deve ser ressaltado é a propriedade com que o estudioso trata a produção poética. De forma atual e bem fundamentada teoricamente, Sousa Dias rompe de vez com o paradigma romântico da subjetividade no que envolve o tema de seu livro.

No capítulo "Poesia, arte bilíngüe", Sousa Dias mostra que "a grande poesia não deve ter vocação realista no sentido corrente". Deve ir além, no campo da imagética, possibilitando "ver mais realidade", através de um poder sensível, não intelectual, de "revelação ontológica, cosmológica (ao contrário do esteticismo)" (p. 8). 
Portanto, a poesia se faz em um cotidiano não imediato, capaz de trazer à visão comum dimensões do real que muitas vezes passam despercebidas.

Tendo a poesia a potencialidade de olhar de forma ímpar o seu entorno, acaba por criar uma nova dimensão de real - ainda que seu material básico parta da concretude e sua ferramenta seja a língua comum. A poesia usa a língua-mãe para revelar o que ela própria não revela. Para isso, faz uso de uma espécie de jogo, inventando uma língua na língua, forçando contra os limites e as impossibilidades da linguagem, "violência contra a lingua comum" (p.9). Sendo assim, a poesia surge como uma "voz bilingue", através da qual a língua-mãe é, a um só tempo, falada e não falada, dizendo respeito a um idioma preciso, deixando, também, de ser restrita ao seu domínio. E essa violência da poesia contra a linguagem, acaba sendo contra a sensibilidade também. A perdição frente a um poema é flagrante, uma vez que conhecemos os signos, mas não conseguimos construir imediatamente um significado, um entendimento a contar apenas com os recursos da língua comum, da língua-mãe. Portanto, a linguagem poética conduz a uma "auto-superação do sentir", ao "acesso a uma sensibilidade sem medida pessoal ou até mesmo bumana" (p.10).

Se a língua comum tem como objetivo fazer referência ao real, na poesia a intenção é outra. Sua referência é a vida, mas não com o intuito de exprimir sentimentos ou a vida, mas por criar vida. Poesia não é sentimento, é linguagem, afirma Sousa Dias. A emoção fixada no poema é uma sensação criada com palavras, experiências de linguagem, de transmissão emocional pela linguagem. As emoções pessoais do poeta são erguidas a um plano emotivo impessoal - o eu do poema não é o eu do poeta (enfatiza Sousa Dias uma afirmação sempre importante para ser lembrada) -, a traços (picturais e musicais) de emotividade pura. "A emoção não é causa mas efeito do poema, não é um vivido-exprimido mas um possivel (uma emoção possivel) produzido" (p.11). Assim, a poesia faz "ver num dizer o que, no ser, não é dizivele?' (p.15). Não há outra forma a não ser pela abertura de uma percepção rumo a um Fora, mas que só é acessível a partir de dentro (da linguagem operada pela poesia). "Inventar uma língua nova, uma heterolíngua poética até o limite, forçando um desvio da significação referencial" (idem). Em resumo,

Ela (a poesia) faz-se com as palavras práticas da linguagem quotidiana, mas para as recombinar segundo outras regras e assim constituir, por desvio cria- 
tivo, uma 'outra' língua, uma língua de imagens, uma estranha língua pictural. Para criar com elas, com seu jogo combinatório alógico em 'sintaxe de excepção', com suas surpreendentes aproximações e afastamentos decorrentes desse jogo, as suas consonâncias e dissonâncias rítmicas e semânticas, sentidos que não são já significações mas visões, 'vidências' na acepção rimbaldiana, efeitos extra-linguísticos: uma transcendência luminosa das palavras, palavras alucinadas, palavras-luz ( p.16).

A palavra na poesia surge não como signo referencial, "signo de", significado que remete a outra coisa, mas somente como "signo", elemento autoreferente, ou seja, produz sua própria realidade significada.

Em "A experiência poética", dentre os vários mitos em circulação acerca da poesia, que Sousa Dias acaba por romper, está a idéia de que não se trata de uma expressão literária do vivido. O sucesso do poema, a exatidão das suas palavras, se encontram, paradoxalmente, no silêncio: margem exterior da linguagem presentificada como sensação do indizível. A poesia passa a ser uma linguagem que "nada diz", ou melhor, uma linguagem que força os limites do dizível, tangenciando a impotência do dizer.

O fato de existir uma impessoalidade - a voz poética não ser de ninguém - permite ao poema tornar-se voz de outros, ser por outros apropriado como "seu". Apossando-se dessa visão de alteridade, o leitor, por exemplo, passa a ter a experiência de "abertura da sensibilidade para lá do borizonte natural dos dados sensiveis, de fixação num dizer de sensações do indizível das coisas mais simples" (p.29). Essa função de ruptura, de embate da poesia com a linguagem, que é comum a outras artes, é o que Deleuze, citado por Sousa Dias, afirma: passar pelo finito, confrontar-se com o finito, para restituir o infinito. A poesia seria, portanto, como afirma a tese de Jean-Luc Nancy, uma resistência à infinitude vocacional da linguagem, ou seja, sua tendência em querer ser capaz de tudo abranger, de tudo significar, "pretensão constitutiva da linguagem a dizer a totalidade do ser" (p.32).

Portanto, por um lado, temos um sistema que visa unicamente à comunicação (língua comum), a qual tem a pretensão de tudo nomear; por outro, surge a poesia e re-significa o signo arbitrário (Saussure) desse sistema sem o descaracterizar, porém, trazendo algo que está imerso na palavra - aflorando determinada sonoridade, uma imagem, um jogo de palavras etc. - não antes reconhecido fora desse âmbito poético. De fato, nosso sistema linguístico 
- por não ser icônico, mas simbólico - tem por natureza uma disposição linear e imposta; é nesse sentido que a poesia - como toda arte - surge como resistência a um sistema determinante que pretende tudo abranger (Nancy), conduzindo sempre a uma condição estática que não vai além do significado sensu comum praticado por um grupo linguístico.

A poesia, diferentemente, abre nossa percepção a uma imagética não antes percebida, um visão diferente, de "mais realidade" do real. A prova da finitude e falibilidade da linguagem comum é a própria poesia quando se apossa dos signos distorcendo-os, re-semantizando-os. O uso frequente (coloquial) de uma palavra conduz à perda do seu significado abrangente, uma espécie de banalização semântica do vocábulo. A poesia ao tomá-la, a lança para fora da língua comum, mostrando um ângulo posterior (como em Picasso) escondido da palavra, ou melhor, que a língua comum nos impedia de ver. Então, constata-se a capacidade de abrir o signo - o poema - para além, sem mais fechá-lo, não dizendo a totalidade do ser, mas o infinito deleuziano.

Assim, a poesia surge, na verdade, como uma experiência criada ou fixada na linguagem através de uma transformação alucinatória da experiência comum, assinalada por percepções de um excesso do real, abrindo-se a uma outra visibilidade ou sensibilidade: "imagens-sensação (geométricas ou rítmicas, figurais ou abstratas, materiais ou vąias) ao mesmo tempo ópticas e cerebrais, imagens-pensamento de um cérebro-olho" (p.35).

No capítulo "Com que palavras e sem que palavras?", Sousa Dias procura mostrar o pensamento teórico interiorizado na poesia de Manuel Antonio Pina, tal como apreende nas entrevistas de Dito em voz alta, no que diz respeito à autonomia da palavra poética e da consciência de um "não saber" inerente à escrita: "domínio da obscuridade" (p.37). É importante salientar a aversão do poeta às incursões teóricas, dizendo que a poesia seria por si só o seu próprio pensamento ou a teorização sobre poesia.

A partir da análise da produção de Manuel Antonio Pina, o autor propõe uma exposição, que se dá através de "traços correlativos mais ou menos recorrentes" (p.38), como a idéia do escritor como leitor de si mesmo, que por sua vez afetará o leitor através do poema, revelando, tornando dizível o que em nós e no mundo permanece indizível ou incompreensível, "algo que o leitor já sabia mas não sabia que sabia" (p. 39). Sobre autonomia da poesia, o autor pontua, a figuração teatral da pessoa (o "eu" e o "tu” como personagens) que se encontra presente 
em um tempo que sobrevoa o tempo vivido, uma "intima presença do poeta diante de sua própria ausência ou impossível identidade" (p.41), uma voz impessoal.

As idéias poéticas nascem das palavras, "do seu jogo na topologia do poema, dos efeitos visuais e musicais desse jogo" (p. 42), e essas são o que justifica e dá prestígio ao poema como arte, as imagens que constrói com palavras e com um além das próprias palavras, um "fora” delas indizível só possível através delas, forçando ao limite da linguagem. A consciência do "não saber" - domínio da obscuridade poética - está no fato de que a poesia "não está no que dir mas no indiquivel do que diz. e que é a razão desse dizer" (p.44). A voz poética surge como "infalável”, aquela que fala ou tenta falar sob a linguagem e a memória. De uma muda "revelação" de nós e do Ser por detrás das cortinas das palavras e das lembranças, que o tempo pode apagar, deformar ou distorcer. Fica, então, evidente, nesse capítulo, a idéia de autonomia da palavra poética, nuclear ao seu estudo.

"Partir, evadir-se, traçar uma linha - Deleuze e a literatura" finaliza O que é a poesia? nos revelando como a literatura ocupa lugar importante no pensamento do autor de O que é a filosofia? (livro escrito em parceria com Félix Guattari). Tal articulação na filosofia deleuziana se dá por sua particularidade em usar o dado extra-linguístico com outra finalidade no campo da literatura (p.47). O filósofo valoriza o que Sousa Dias define como um paradoxo constituinte da criação, uma vocação não literária. "O grande escritor, diz. Deleuze, nunca escreve para se tornar escritor mas outra coisa que passa pela escrita mas a ultrapassa e que ao mesmo tempo faz da escrita mais do que escrita" (Idem)

Para Deleuze, a literatura não deve ter a intenção de dar forma a uma matéria vivida, de recriar a vida real das pessoas como vivência imaginária, mas sim de inventar linhas possíveis, de abrir a novas possibilidades, fixar passagens (ou devires) e fazer delas "monumentos" estéticos. Criar visões e sensações de uma vida não pessoal, de uma possibilidade existencial distinta dos estados vividos, uma abertura ao ilimitado e ao infinito de uma vida possível. "Não há arte literária, para Deleuze, sem essa travessia, sem ser essa travessia, essa passagem do horizonte do vivido, essa entrada numa outra vida" (p.49).

Para o autor, partindo de Deleuze, o escritor inspira-se no vivido, parte do "eu", dos seus estados "perceptivos e afectivos", para ultrapassá-los e aderir a um outro tipo de percepção e afecção que excede todas as vivências, extraindo novas sensações e fazendo viver (na literatura) sua própria vida. Tais afectos e perceptos são acontecimentos criados pela literatura que os 
criam pela linguagem, mas não acontecem na linguagem, são-lhe exteriores, ocorrem num limite exterior da linguagem - e não à linguagem, separado desta. Não existe fora dela, antes é o seu fora, "a sua ponta extrema, laminar"(...), "num silêncio das próprias palavras preenchido por visões e audições"(p.54), como que entrando em transe, onde as palavras desatassem já não a dizer mas a pintar e a cantar; sendo assim, para Deleuze, a literatura é essencialmente música e pintura. Ao criador do texto poético mostra-se inevitável "ferir a sintaxe da sua língua, de torcê-la ou distorcê-la, de violentar o dizivel como condição de atingir o exterior assintático da linguagem onde já só é questão de ver e ouvir" (idem). Assim, o escritor encontra seu estilo através de uma nova "sintaxe desviante", "incorreta", escavada na sintaxe normativa da sua língua, como condição de vidência, como "Idéias estéticas (sensiveis) autônomas, impessoais" (p.55).

No encerramento, o filósofo português encontra Deleuze como intercessor de suas incursões percucientes pela análise contemporânea da poesia, frisando-a como "a criação de uma língua de imagens, língua imagética pura" (p.58).

Sousa Dias traçou, com O que époesia?, uma concepção estética que permite contradizer uma visão romântica ainda vigente acerca de subjetividade e escrita. Ao responder diretamente o que é poesia, revela o interior da questão; não apenas do fazer poético, mas do ser poesia como linguagem autônoma, que mesmo criada por alguém, desprende-se para viver uma realidade própria a cada leitura, em cada tempo, restituindo o infinito, tão caro e inaceitável à razão humana.

\section{Referências Bibliográficas}

PINA, Manuel António. Dito em voz alta. Coimbra: Pé de Página Eds., 2007 DIAS, Sousa. O que é poesia? Coimbra: Pé de Página Editores, 2008. 